\title{
Editorial: Moving on
}

\author{
Philip Machanick (iD) sacj.editor@gmail.com \\ Department of Computer Science, Rhodes University, South Africa
}

\section{Introduction}

This is my last regular issue of South African Computer Journal before Katherine Malan takes over final editing of the July 2022 issue. I served two five-year terms as editor-in-chief and am pleased to hand the journal over as a going concern.

This issue marks two other changes. It is the last issue to be completed by production editor James Dibley and one of our Information Systems editors, Caroline Kene, will be stepping down.

In my previous editorial, I gave a retrospective of how $S A C J$ has advanced since I took over; this time I want to reflect on how Covid-19 has made things difficult in academia, before listing contents of the current issue.

\section{Covid-19 Retrospective}

Perhaps it is premature to do a retrospective on Covid-19 as the Omicron variant is growing apace at time of writing. Nonetheless we have learnt from operating under a pandemic. I give some personal reflections that may or may not apply to others.

$S A C J$, despite all the disruptions of the Covid-19 pandemic, has brought out each issue on schedule. However, things have been slowed down: finding responsive reviewers has been more difficult than before and this issue is relatively thin.

In my own courses, 2020 was a particularly difficult year. One of my classes, a secondyear computer architecture course, started right after South Africa's first lockdown. Much of the 4-week course was run with no certainty of access to computers and Internet. The course previously relied heavily on the practical component, mostly coding in MIPS assembly language, and I had to make major adjustments.

In 2021, I took a highly adaptive approach to the course. In retrospect, I invented a new approach to pedagogy that I now call adaptive agile blended learning. It draws on the core ideas of agile development and blended learning (not a novel idea (Tesar \& Sieber, 2010)) but rather

\footnotetext{
Machanick, P. (2021). Editorial: Moving on [Editorial]. South African Computer Journal 33(2), vii-viii. 10.18489/ sacj.v33i2.1042

Copyright (C) the author(s); published under a Creative Commons NonCommercial 4.0 License (CC BY-NC 4.0). $S A C J$ is a publication of the South African Institute of Computer Scientists and Information Technologists. ISSN 1015-7999 (print) ISSN 2313-7835 (online).
} 
than a fixed framework for applying these methods, I emphasize close attention to how a class is coping and rapid adjustments to the approach as problems arise - hence adaptive.

In a class survey, while there were some negatives, I had some of the most positive comments in any course survey I have run.

Another aspect of Covid-19 is countering disinformation. I have spent a lot of time on social media and writing for popular media - not usual academic activities but those with the knowledge to take part in public debate need to step up when they are needed. The extent of disinformation and anti-science contrarianism has not been seen since the height of AIDS denial.

\section{In this issue}

In this issue, we have three research papers:

- Mpangase et al: "nf-rnaSeqCount: A Nextflow pipeline for obtaining raw read counts from RNA-seq data"

- Muchenje and Botha: "Consumer-centric factors for the implementation of smart meters in South Africa"

- Pillay and Van der Merwe: "Big Data Driven Decision Making Model - a case of the South African Banking Sector"

We also provide a short communication which aims to clarify some best practices for preparing submissions to $S A C J$, with particular attention to preparing publication-ready reference lists.

\section{References}

Tesar, M., \& Sieber, S. (2010). Managing blended learning scenarios by using agile e-learning development. Proc. IADIS International Conference E-Learning, 2, 125-129. 